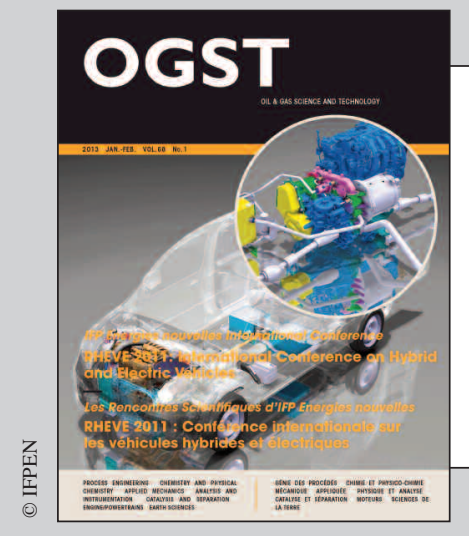

Dossier

This paper is a part of the hereunder thematic dossier published in OGST Journal, Vol. 68, No. 1, pp. 3-178 and available online here

Cet article fait partie du dossier thématique ci-dessous publié dans la revue OGST, Vol. 68, n 1 , pp. 3-178 et téléchargeable ici

DOSSIER Edited by/Sous la direction de : A. Sciarretta, F. Badin et J. Bernard RHEVE 2011 : International Conference on Hybrid and Electric Vehicles RHEVE 2011 : Conférence internationale sur les véhicules hybrides et électriques

Oil \& Gas Science and Technology - Rev. IFP Energies nouvelles, Vol. 68 (2013), No. 1, pp. 3-178

Copyright (C) 2013, IFP Energies nouvelles

\section{$3>$ Editorial}

$13>$ Analysis and Experimental Implementation of a Heuristic Strategy for Onboard Energy Management of a Hybrid Solar Vehicle

Analyse et expérimentation d'une stratégie heuristique pour la gestion d'énergie à bord d'un véhicule hybride solaire

G. Coraggio, C. Pisanti, G. Rizzo and M. Sorrentino

23 > Open Issues in Supervisory Control of Hybrid Electric Vehicles: A Unified Approach Using Optimal Control Methods

Questions ouvertes sur la supervision énergétique des véhicules hybrides électriques : une approche unifiée par la théorie de la commande optimale

L. Serrao, A. Sciarretta, 0. Grondin, A. Chasse, Y. Creff, D. Di Domenico, P. Pognant-Gros, C. Querel and L. Thibault

35 > Optimization of Hybrid Power Trains by Mechanistic System Simulations

Optimisation de groupes motopropulseurs électriques hybrides par simulation du système mécanique

T. Katrašnik and J.C. Wurzenberger

51 > A Phenomenological Heat Transfer Model of SI Engines - Application to the Simulation of a Full-Hybrid Vehicle

Un modèle phénoménologique de transfert thermique au sein de moteurs à allumage commandé - Application à la simulation d'un véhicule full-hybride

R. Dubouil, J.-F. Hetet and A. Maiboom

$65>$ Battery Electric Vehicle (BEV) or Range Extended Electric Vehicle (REEV)? - Deciding Between Different Alternative Drives Based on Measured Individual Operational Profiles

Véhicule électrique à batteries (BEV) ou véhicule électrique à prolongateur d'autonomie (REEV) ? - Choisir entre différents entrânements alternatifs sur la base de profils opérationnels individuels mesurés

S. Marker, B. Rippel, P. Waldowski, A. Schulz and V. Schindler

$79>$ Assessment by Simulation of Benefi ts of New HEV Powertrain Configurations

Évaluation par simulation des bénéfi ces de nouvelles chaînes de traction hybrides

N. Kim and A. Rousseau
95 > Dual Mode Vehicle with In-Wheel Motor: Regenerative Braking Optimization

Véhicule bi-mode avec moteurs roues : optimisation du freinage récupératif

G. Le Solliec, A. Chasse, J. Van-Frank and D. Walser

109 > Engine Downsizing and Electric Hybridization Under Consideration of Cost and Drivability

Réduction de taille moteur et hybridation électrique avec considérations de coût et de performance de conduite

S. Ebbesen, P. Elbert and L. Guzzella

117 > Representative Midwestern US Cycles: Synthesis and Applications Cycles représentatifs du Middle West américain : synthèse et applications

T.-K. Lee and Z.S. Filipi

127 > A Review of Approaches for the Design of Li-lon BMS Estimation Functions

Revue de différentes approches pour l'estimation de l'état de charge de batteries Li-ion

D. Di Domenico, Y. Creff, E. Prada, P. Duchêne, J. Bernard and V. Sauvant-Moynot

137 > Experimental Assessment of Battery Cycle Life Within the SIMSTOCK Research Program

Évaluation expérimentale de la durée de vie de la batterie dans le programme de recherche SIMSTOCK

P. Gyan, P. Aubret, J. Hafsaoui, F. Sellier, S. Bourlot, S. Zinola and F. Badin

$149>$ Smart Battery Thermal Management for PHEV Efficiency Une gestion avancée de la thermique de la batterie basse tension de traction pour optimiser l'efficacité d'un véhicule hybride électrique rechargeable

L. Lefebvre

$165>$ Parameterization and Observability Analysis of Scalable Battery Clusters for Onboard Thermal Management

Paramétrage et analyse d'observabilité de clusters de batteries de taille variable pour une gestion thermique embarquée

Xinfan Lin, Huan Fu, Hector E. Perez, Jason B. Siege, Anna G. Stefanopoulou, Yi Ding and Matthew P. Castanier 


\title{
Battery Electric Vehicle (BEV) or Range Extended Electric Vehicle (REEV)? - Deciding Between Different Alternative Drives Based on Measured Individual Operational Profiles
}

\author{
S. Marker*, B. Rippel, P. Waldowski, A. Schulz and V. Schindler \\ Technische Universität Berlin, Institute of Land and Sea Transport Systems (ILS), Division of Automotive Engineering, \\ Sekr. TIB 13, Gustav-Meyer-Allee 25, 13355 Berlin - Germany \\ e-mail: stefanie.marker@tu-berlin.de - rippdhli@mailbox.tu-berlin.de - paul.waldowski@tu-berlin.de \\ alexandra.schulz@kfz.tu-berlin.de -volker.schindler@tu-berlin.de \\ * Corresponding author
}

Résumé - Véhicule électrique à batteries (BEV) ou véhicule électrique à prolongateur d'autonomie (REEV) ? - Choisir entre différents entraînements alternatifs sur la base de profils opérationnels individuels mesurés - Récemment, un grand nombre de concepts d'électrification des groupes motopropulseurs et une large variété correspondante de configurations disponibles ont été présentés au public. Tous possèdent des avantages et des inconvénients pour le client. Cet article traite d'un outil permettant au client de sélectionner le groupe motopropulseur le plus adapté à ses besoins individuels. L'approche présentée se focalise sur les véhicules BEV (Battery Electric Vehicle - véhicule électrique à batteries) et REEV (Range Extended Electric Vehicle véhicule électrique à prolongateur d'autonomie) et est caractérisée par une procédure en trois étapes :

- le comportement individuel au volant du client est évalué ;

- les cycles de conduite individualisés et les habitudes opérationnelles comprenant le kilométrage journalier sont déterminés ;

- en appliquant ces cycles individualisés, des modèles numériques de concepts de groupe motopropulseur alternatif sont réalisés afin de simuler la consommation d'énergie. L'étude révèle que le dimensionnement de la batterie constitue l'élément le plus important. Un véhicule REEV possédant une batterie plus petite serait plus efficace qu'un véhicule BEV : pour une autonomie donnée de $50 \mathrm{~km}$, le véhicule BEV parcourt $50 \%$ des kilomètres totaux (correspondant à $90 \%$ de l'ensemble des distances journalières) alors que le véhicule REEV parcourt $100 \%$ de l'ensemble des distances journalières, dont $70 \%$ en mode électrique. Ceci amène à une plus faible émission de $\mathrm{CO}_{2}$ par rapport à l'utilisation associée des véhicules $\mathrm{BEV}$ et des véhicules conventionnels. Le véhicule REEV possédant une batterie plus petite est amorti plus tôt qu'un véhicule conventionnel. L'influence exercée par le type d'usage individuel peut être traduite en coûts d'exploitation. Le conducteur urbain d'un véhicule REEV parcourt $85 \%$ des trajets en mode électrique et bénéficie de coûts d'exploitation plus faibles que le conducteur interurbain d'un véhicule REEV parcourant $64 \%$ des trajets en mode électrique. 


\begin{abstract}
Battery Electric Vehicle (BEV) or Range Extended Electric Vehicle (REEV)? Deciding Between Different Alternative Drives Based on Measured Individual Operational Profiles - In recent years, a large number of concepts for drive train electrification and a corresponding broad variety of available drive train configurations were presented to the public. They all have their pros and cons for the customer. This paper discusses a tool enabling the customer to select the drive train which is best suited to his individual purposes. The presented approach focuses on BEV and REEV and is characterized by a three-step procedure:

- the customer's individual driving behaviour is measured;

- individualized driving cycles and operational habits including the daily kilometrage are derived;

- numerical models of the alternative drive train concepts are run to simulate the energy consumption by applying these individualized cycles.

The study reveals that battery sizing is the most important component. It would be more efficient to use a REEV with a smaller battery instead of a BEV: at a given range of $50 \mathrm{~km}$ the BEV covers $50 \%$ of the kilometers (corresponding to $90 \%$ of all daily distances) while the REEV covers $100 \%$ of all daily distances, out of it $70 \%$ on electric driving. This leads to less $\mathrm{CO}_{2}$ emission compared to the combined use of BEV and conventional cars. The REEV with the smallest battery is amortized first referred to conventional cars. The influence of the individual usage pattern can be translated to operational costs. The REEV urban driver covers $85 \%$ by electric driving and has thus lower operational costs than the REEV inter-urban driver with $64 \%$ electric driving.
\end{abstract}

\section{INTRODUCTION}

The ongoing electrification of passenger car propulsion systems is accompanied by a large and still increasing number of variants for electric and hybrid drive trains. The energy saving potential of a given electric vehicle (xEV) highly depends on its operational profile, thus using the same $x E V$ - different usages and even drivers can result in markedly different energy savings compared to a conventionally propelled vehicle. In case of hybrid electric vehicles, such as the Range Extended Electric Vehicle (REEV), the energy saving potential is influenced by the drive train topology. Therefore, changes in the dimensions of crucial components like battery size can result in much different operational energy use.

Thus, knowing the exact individual usage pattern of a customer, the Original Equipment Manufacturer (OEM) - in theory - could provide him an adequate propulsion system, which matches his needs and allows for maximal energy savings, minimal emissions or minimal operational cost. In practice, he could offer him a range of options to tailor the drive train as good as possible to his needs and he could advise him to choose among battery sizes in a rational way.

Regarding the possibility of recharging the REEV battery at the grid, there are much more degrees of freedom in drive train dimensioning. In this case, not only the individual driving cycle but also the tradeoff between purely grid-electric operation (mainly defined by maximum values of energy and power of the battery) and the engine-based operation become decisive. Long distances between recharging stations influence the energy efficiency, the mix of energies needed and costs of the vehicle. Plug-in Hybrid Electric Vehicles (PHEV), REEV and Battery Electric Vehicles (BEV) are currently under intensive research but, so far, there is no option which fits the requirements of all users. As batteries tend to stay the most expensive component of electrified vehicles, they have to be minimized in size and maximized in usage to obtain the economically most feasible power train option. Minimizing the battery also reduces the amount of grid energy used but differently for different driving cycles, especially for different kilometrages to be covered between grid connects. A broad variety of individual solutions results from the combination of some or all of the drive train architecture options because they can be assembled in various manners and sizes. However, the challenge is to identify the optimal configuration.

A variety of publications addresses the potential of grid charged electric vehicles. Three battery sizes of each, PHEV and REEV, are investigated and compared regarding their efficiency for different cycles in [1]. A cost-benefit analysis of PHEV is issued in [2]. A Total Cost of Ownership (TCO) analysis is presented in [3] for a REEV and three differing ranges. Daily kilometrage distributions are applied in [3] and [2] to estimate the ratios driven in Charge Depleting Mode (CDM) and Charge Sustaining Mode (CSM). These publications also aim to estimate the e-driven range optimum for a 
preferably large group of drivers, applying utility factor curves made of average profiles of a broad range of individual users. Likewise, the driving cycles, which are used to estimate the energy consumption, base on real but standardised velocity distributions. The procedure addressed in this paper exceeds this generalised approach: it focuses the efficiency consideration for an individual user. The approach relies on a measurement technique based on a small autarkic GPS data logging system (TU-veLOG), which is used to collect data on the individual operational profiles of private as well as commercial vehicles (cf. $[4,5])$.

The particular characteristics of CDM and CSM are issued in Section 3.1.

\section{METHODOLOGY}

To frame the requirements of an optimal drive train a conglomerate of data is investigated. It is based on individual driving profiles, modeled consumption values and customer's specific requirements:

The GPS-based TU-veLOG data logger records the driving behaviour and velocity profiles of the current vehicle which is intended to be replaced by the new one with the ideal power train configuration. The TU-veLOG data serve as input parameters for vehicle models generating consumption information and for the optimisation process. It results in the selection of the optimal configuration among those taken into account. Mathematically, this can be formalized as an optimization process, i.e. a target function is minimized with regard to a set of boundary conditions. Usually, the target function will be a cost factor. Other targets can be implemented as well, e.g. the $\mathrm{CO}_{2}$ emissions or the use of non-crude oil primary energies, depending on their profit in political decision making both nationally and in the EU.

For realization, a multi-stage procedure is suggested. First, the real-time utilization of a vehicle is logged. Second, information characterizing the individual driving patterns such as the distribution of daily driven distances as well as individual driving cycles are derived from the raw data. Third, all relevant power train options are modeled including the range of sizes allowable for relevant components like the battery. This can also be done for the range of options offered by some preselected OEM or for some class of vehicles. Four, in an optimization process the energy consumption is simulated for the power train options. It should be pointed out that the optimization results are derived from the individual driving cycle. Finally, the results are re-assessed taking into account purchase costs and operating expenses of the vehicles.

\section{PROCEDURE OF INDIVIDUAL DRIVING CYCLE ESTIMATION}

The following sections address the particular drive train optimization steps. They are demonstrated applying the results of a user group consisting of 50 persons mainly active in the Berlin-Brandenburg area. An example visualizes how the approach impacts cost efficiency and emission calculations of REEV with different electric ranges.

\subsection{Measurement Technique}

The measurement technique, TU-veLOG, applies a data logger usually meant for tracking packages. The GPSbased device measures position, velocity and other important data, which are logged on an integrated storage. The logged data allow to analyze the individual driving behaviour. They are analyzed automatically, generating essential insights into the usage behaviour, for instance the frequency distribution of the daily driving distances. These data permit to investigate the suitability of a certain drive train concept for an individual user or user group. For instance, BEV charging strategies could be evaluated applying diurnal driving profiles and parking information. The upper panel of Figure 1 shows the diurnal variations of 50 private users in the Berlin metropolitan area. The probands should comprise a broad variety of users even though they are not representative in a statistical sense. It can be pointed out that at least six hours could be reserved for night time charging. The bottom panel of Figure 1 depicts the frequency distribution of the diurnal driven distances for the same user group. About $87 \%$ of all distances range below $50 \mathrm{~km}$ (red curve). However, only $49 \%$ of the total kilometrage is covered by this $87 \%$ portion (green curve). Taking into account the first $50 \mathrm{~km}$ of all longer trips, it amounts to $68 \%$ of the total driven distance (black curve). These values should have a significant impact on the drive train design of REEV, since they allow to deduce distinct usage ratios of pure electric and combustion-supported propulsion.

\subsection{Individual Driving Cycles}

The way of driving significantly influences a car's energy consumption and $\mathrm{CO}_{2}$ emission.

An individual drive train design requires an individual driving cycle. For automated generation of these velocity-time profiles a distinct tool, the Individual Driving Cycle Builder (IDCB), was developed, following the methodology used in [6]. In the TU-veLOG data analysis 

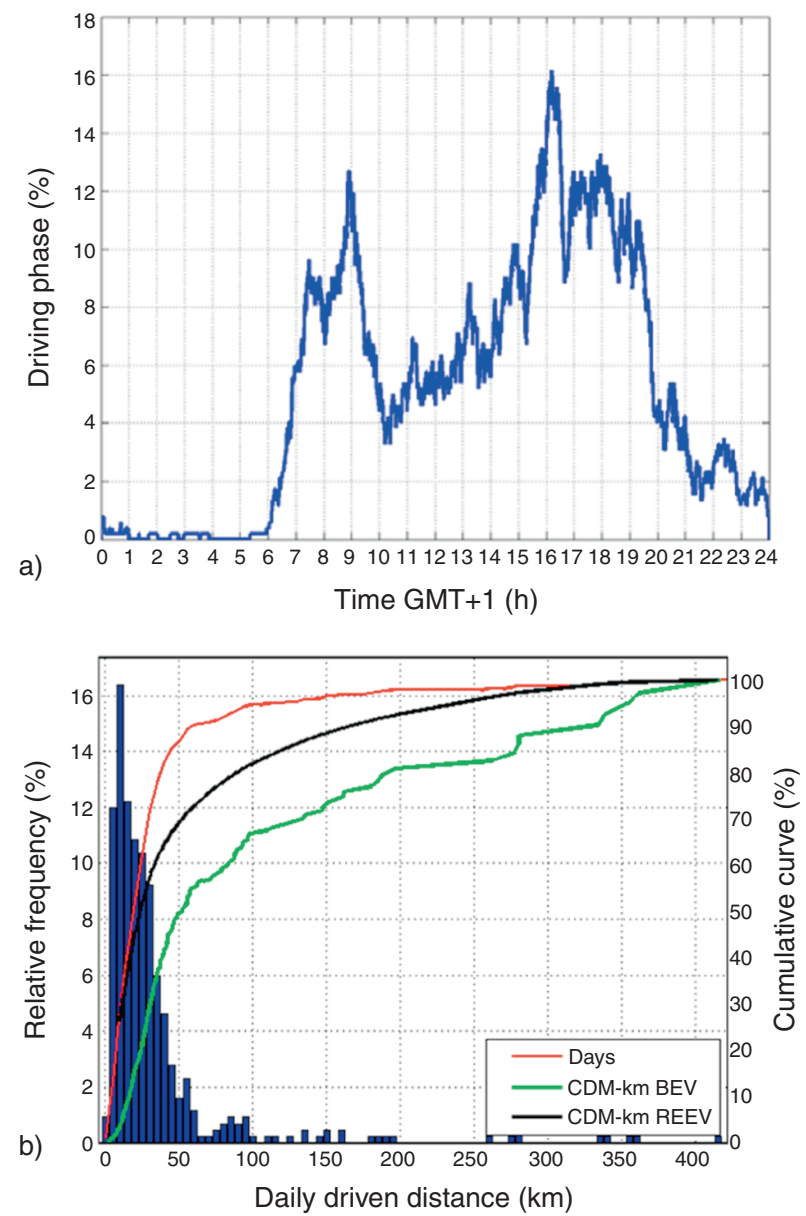

Figure 1

a) Usage time and b) distribution of daily driven distances. The daily driven distances are reproduced in Figure 9 where the legend is explained in detail.

procedure the cycle is generated using pattern classification. This approach sorts so-called kinematic sequences into different classes applying a statistical evaluation. A kinematic sequence is composed by a standing phase and the subsequent driving phase. It is directly followed by the next kinematic sequence. Figure 2 visualizes a drive's splitting into three kinematic sequences.

In a next step, each kinematic sequence is further allocated into one of twelve classes, which are defined by average speed, stop rate, stop frequency and average acceleration. The classification additionally specifies a segment as urban, rural or motorway trip. Subsequently, the segments are stringed together according to their frequency distribution and pooled to a urban trip cycle, rural trip cycle, or motorway trip cycle, respectively.

The length of the driving cycle compromises exactness and expenditure of time. The longer the generated cycle,

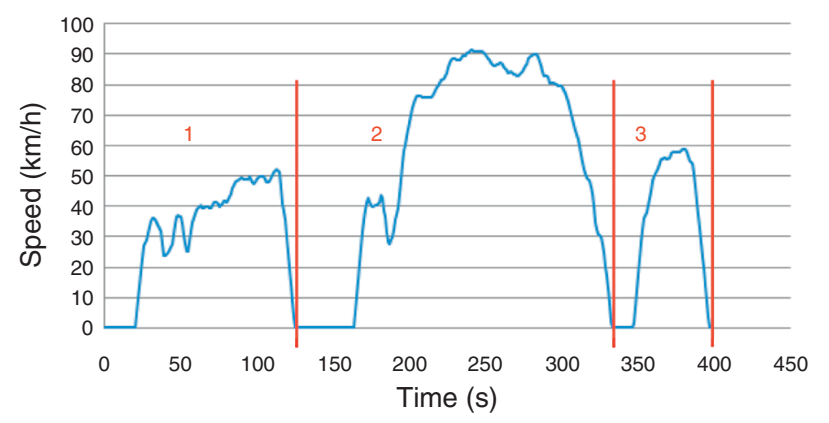

Figure 2

Three kinematic sequences consisting of a standing phase and a driving phase each [7].

the closer it matches reality. However, the simulation time is increasing with the driving cycle length, which can be preset in the IDCB [7].

Figure 3 shows an example distribution of the different classes in the whole data set and in the cumulated driving cycle composed of urban, rural and motorway parts. Blue bars symbolize the class distribution of all segments taken from the raw data. For the green bars, infrequently occurring classes have been eliminated. Brown bars depict the class distribution of all segments taken from the driving cycle.

It can be seen that the frequently driven urban trip segments are realistically reproduced in the driving cycle (left part). All classes, which have been run by the driver in reality (the classes 1-5 in this example), can be recovered in the generated driving cycle with the corresponding distribution. Due to the cycle time limit and the sparse occurrence of motorway trips in the original driving profile (right part), only one of two segments (class 12) of motorway driving has been overtaken in the cumulated driving cycle.

Beyond generating individual driving cycles of single drivers the IDCB is able to develop user group driving cycles and distance-depending driving cycles. Figure 4 faces the individual driving cycles, derived from a proband group of 50 people mobile in the Berlin metropolitan area. The urban trip is characterized by a lot of start-stop manoeuvres and short driving intervals with moderate speed values $(<65 \mathrm{~km} / \mathrm{h})$. On the rural trip, longer driving intervals at higher speed values $(50-100 \mathrm{~km} / \mathrm{h})$ are interrupted by short stop situations from time to time. The motorway trip is marked by continuous operation on speed values $>100 \mathrm{~km} / \mathrm{h}$.

Distance-depending driving cycles have special impact on REEV investigations. As illustrated in Figure 5, long diurnal distances are usually correlated with high average speed values. 

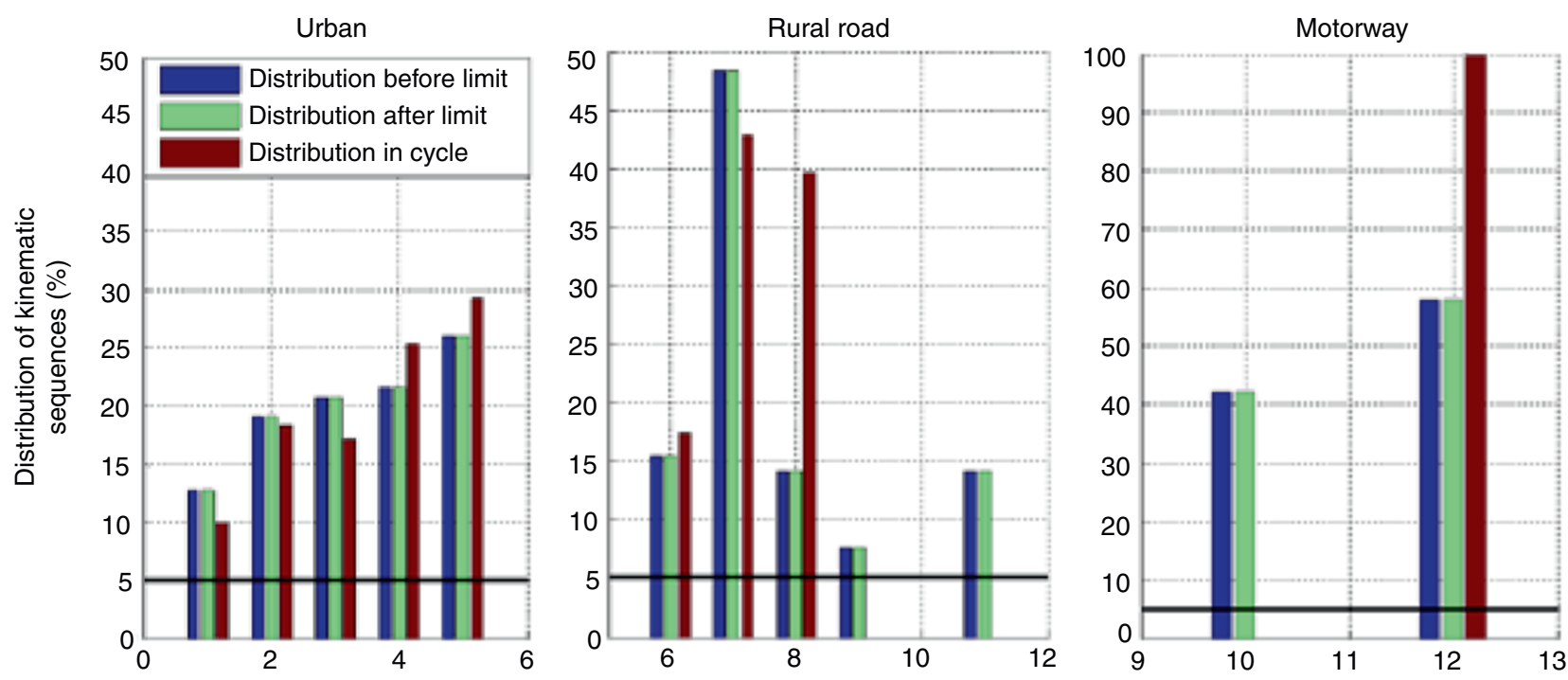

Figure 3

Class distribution in the IDCB.

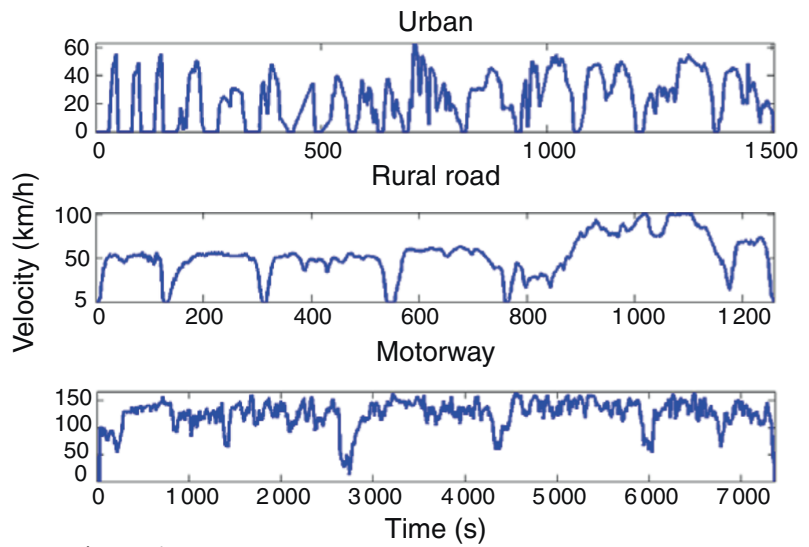

Figure 4

Individual driving cycle, separated for urban, rural and motorway trips. Regard the different time and speed scaling in the subpanels. It is chosen to match the individual characteristics of each profile.

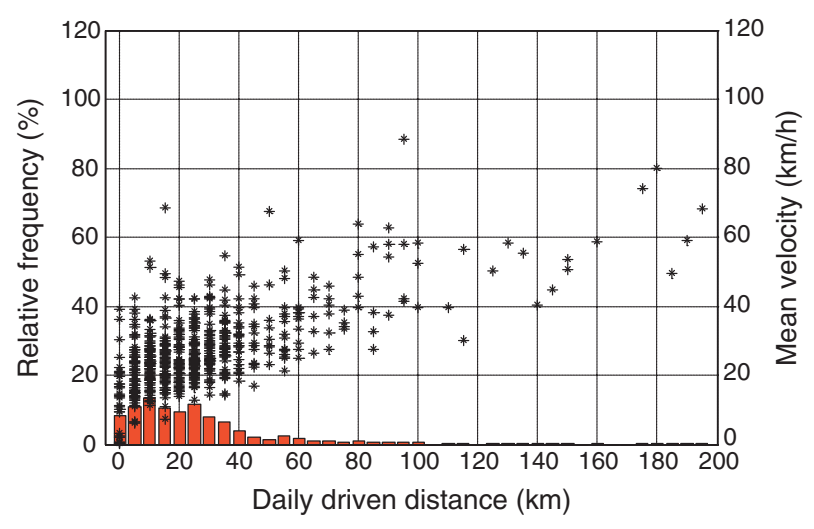

Figure 5

Daily driven distance and average speed.
REEV velocity-time profiles are characterized by a significant difference between short distances and long distances. Short distances are run ideally in the CDM, i.e. with energy from the battery only. Long distances are covered in the CSM which uses the combustion engine to generate enough electric energy to run these distances. A single individual driving cycle comprising both would distort the real conditions. It should not be used to derive the energy demand in CDM and CSM, since different driving profiles are run in CDM (e.g. urban trip) and CSM (e.g. motorway trip) in reality. Consequently, two different individual driving cycles are generated for REEV and PHEV. The following calculation demonstrates the effects of this differentiation on the derived energy demand. First, the energy consumption in CDM and CSM was derived from only one complete data cycle. Second, the energy consumption was composed by the results of a short distance 
TABLE 1

REEV-consumption on trip-dependent cycles

\begin{tabular}{l|c|c|c|c}
\hline Complete-data cycle & Urban & Road & Motorway & Comb. \\
\hline Weighting (\%) & 61 & 32 & 7 & 100 \\
\hline $\begin{array}{l}\text { Average speed } \\
(\mathrm{km} / \mathrm{h})\end{array}$ & 22.6 & 53.1 & 123.6 & 39.5 \\
\hline $\begin{array}{l}\text { CDM cons. } \\
(\mathrm{kWh} / 100 \mathrm{~km})\end{array}$ & 19.0 & 16.2 & 33.2 & 19.1 \\
\hline $\begin{array}{l}\text { CSM cons. } \\
(\mathrm{L} / 100 \mathrm{~km})\end{array}$ & 5.92 & 5.27 & 10.62 & 6.04 \\
\hline
\end{tabular}

\begin{tabular}{l|c|c|c|c}
\hline $\begin{array}{c}\text { Short distance } \\
\text { Cycle }(<50 \mathrm{~km})\end{array}$ & Urban & Road & Motorway & Comb. \\
\hline Weighting $(\%)$ & 78 & 22 & - & 100 \\
\hline $\begin{array}{l}\text { Average speed } \\
(\mathrm{km} / \mathrm{h})\end{array}$ & 23.9 & 45.6 & - & 29.2 \\
\hline $\begin{array}{l}\mathrm{CDM} \text { cons. } \\
(\mathrm{kWh} / 100 \mathrm{~km})\end{array}$ & 16.3 & 14.01 & - & 15.8 \\
\hline
\end{tabular}

\begin{tabular}{l|c|c|c|c}
\hline $\begin{array}{c}\text { Long distance } \\
\text { Cycle }(>50 \mathrm{~km})\end{array}$ & Urban & Road & Motorway & Comb. \\
\hline Weighting $(\%)$ & 35 & 48 & 17 & 100 \\
\hline $\begin{array}{l}\text { Average speed } \\
(\mathrm{km} / \mathrm{h})\end{array}$ & 24.5 & 108.1 & 123.6 & 58.2 \\
\hline $\begin{array}{l}\mathrm{CSM} \text { cons. } \\
(\mathrm{L} / 100 \mathrm{~km})\end{array}$ & 6.05 & 9.64 & 10.62 & 8.56 \\
\hline
\end{tabular}

driving cycle and a long distance driving cycle. The calculations (table 1) are based on a compact class REEV model with a battery size that allows to cover a distance of $50 \mathrm{~km}$. It should be indicated that the battery (and electric machine) power enables to cover also the motorway cycle, this means that we have a 'full power' electric mode on the vehicle.

Investigating the entire group yields a distribution of $61 \%$ urban driving, $32 \%$ rural road driving and $7 \%$ motorway driving on a combined average speed of $39.5 \mathrm{~km} / \mathrm{h}$. The total consumption as derived from the raw data then yields $19.1 \mathrm{kWh} / 100 \mathrm{~km}$ in CDM and $6.04 \mathrm{~L} / 100 \mathrm{~km}$ in CSM.

Next, the following scenario is assumed. The battery is charged once per day. Driving distances below $50 \mathrm{~km}$ are covered in CDM, all other distances via the CSM. Two driving cycles are generated:

- for distances below $50 \mathrm{~km}$,

- for distances above $50 \mathrm{~km}$.

It is assumed, that the combustion engine is not operated for other reasons like heating or air conditioning the interior or because charge depletion is spared voluntarily to a later phase of the diurnal trip.

The short distance profile (distances below $50 \mathrm{~km}$ ) includes $78 \%$ urban driving, $22 \%$ rural road driving and no motorway driving. The average speed is about $29 \mathrm{~km} / \mathrm{h}$. The REEV (only CDM mode) consumption amounts to $15.8 \mathrm{kWh} / 100 \mathrm{~km}$, thus undercutting the complete cycle consumption by about $17.3 \%$. The long distance cycle (distances above $50 \mathrm{~km}$ ) provides an average speed of $58 \mathrm{~km} / \mathrm{h}$. It is connected to a consumption of $8.56 \mathrm{~L} / 100 \mathrm{~km}$ in CSM mode, which differs by $29.5 \%$ from the complete cycle consumption. These results emphasize the importance of the relevant cycle selection when dealing with grid-charged drive trains.

\section{INDIVIDUAL DRIVE TRAIN DESIGN}

Prior to the development of an individual drive train design it is necessary to determine the target function which has to be optimized (minimized). In most cases, it corresponds to the amortization time of purchase costs but it can also concern $\mathrm{CO}_{2}$ emission, fossil fuel consumption, operating costs etc. The optimization is accomplished in three steps as implemented by three sub-models:

- the required power is derived from recorded individual driving data and typical assumptions for gradeability at different velocity levels. A reverse calculation approach in Matlab/Simulink ${ }^{\circledR}$ estimates the vehicle's power demand from velocity-time profiles via efficiency maps;

- the energy consumption values in CDM and CSM are computed iteratively applying a detailed scalable energy-use forward simulation. Different drive train architectures are incorporated using Dymola 6.1 and Matlab/Simulink ${ }^{\circledR}$ tools;

- using an Excel-based cost model for $\mathrm{xEV}(=\mathrm{BEV}$, REEV, PHEV) a rough cost-benefit analysis is determined. The following sections address the simulation models used to determine energy consumption values in CDM and CSM. Information on the Excel-based cost model can be found in [1].

\subsection{Energy-Use Simulation Models}

The presented procedure should be applied for vehicle concepts, which are able to be recharged at the utility grid. This comprises BEV and hybrid concepts like REEV or PHEV with large batteries and grid interface. Typical ranges of conventionally powered vehicles cannot be realized with current $\mathrm{BEV}$ due to insufficient 


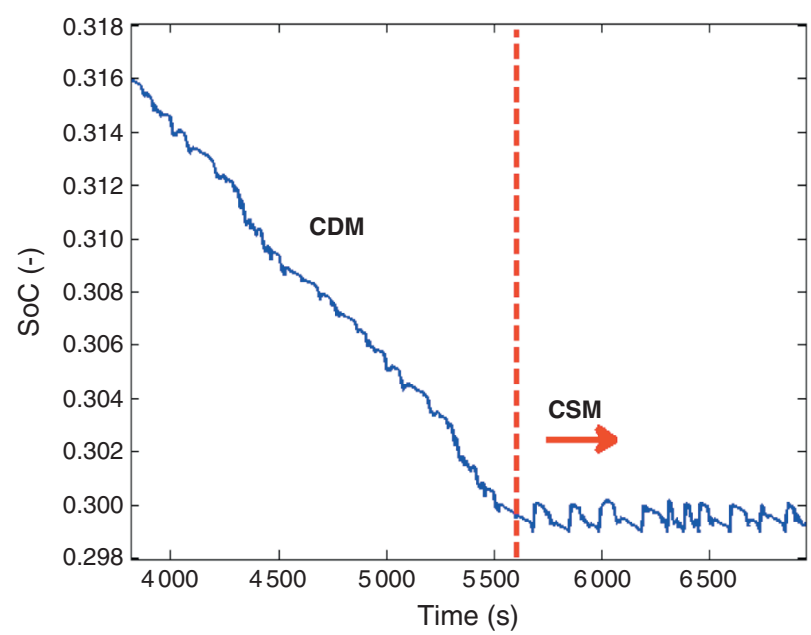

Figure 6

Example of SOC characteristics during CDM and CSM. When a critical SOC range is reached the change from $\mathrm{CDM}$ to CSM occurs in dependence of the operational strategy.

energy density and high purchase costs of the batteries. In a REEV, the selected battery capacity is intended to permit to run most of the diurnal driven distance in the CDM. If the battery is discharged to a defined value, the combustion engine is activated and the vehicle switches to the CSM. The CSM does not aim to recharge the battery but generates enough electric energy to cover long distances. Thus, the range extender's dimensioning has to allow for an average cycle power only; short term power peaks have to be covered by the battery. A simple hybrid control strategy was applied for the investigated REEV model: when the critical discharge value is reached an intermittent engine on/off control logic is activated. It ensures to run the combustion engine continuously at an optimal degree of efficiency. This procedure is executed during low SOC values, since the largest part of the battery capacity is reserved for grid charging and recuperation (Fig. 6).

In this study, the influence of the individual user behaviour on energy consumption and efficiency is illustrated for a REEV. For REEV with a given range the analysis aims to determine how to resolve the range conflict for individual users without countervailing against the $\mathrm{CO}_{2}$ minimization. Furthermore, the results have to be discussed in the context of battery costs and battery ageing processes. The procedure could be also applied for PHEV.

Concerning the drive train topology, an REEV is a serial hybrid concept with the ability to connect to the
TABLE 2

REEV vehicle characteristics as applied in the simulation, crosssectional area, drag coefficient, electric power, basic vehicle mass (except the battery)

\begin{tabular}{c|c|c|c}
\hline $\begin{array}{c}\text { Cross- } \\
\text { sectional area } \\
\left(\mathrm{m}^{2}\right)\end{array}$ & $\begin{array}{c}\text { Drag } \\
\text { coefficient } \\
(-)\end{array}$ & $\begin{array}{c}\text { Electric } \\
\text { power } \\
(\mathrm{kW})\end{array}$ & $\begin{array}{c}\text { Basic vehicle } \\
\text { mass }(\mathrm{kg})\end{array}$ \\
\hline 2.25 & 0.325 & 50 & 1425 \\
\hline
\end{tabular}

grid for recharging and therefore, it is a special form of a PHEV. The REEV can provide its maximum power even in the pure electric operation mode (at de-activated range extender) - provided the battery's SOC is sufficient. In a sense, the REEV can be considered an expansion of the BEV. Numerical models of BEV and REEV have been developed in MATLAB-Simulink ${ }^{\circledR}$. Reversecalculating and map-based models allow for executing the scaling process quickly, while forward-calculating physical models serve as a rule.

Model input parameters which refer to the vehicle class are predetermined and not object to the scaling process. The following analysis is based on a compact class vehicle which is characterized by the parameters listed in Table 2 .

\subsection{Scalable Simulation of Electrified Power Trains}

To asses the influence of the drive train configuration on efficiency and ecology, the models require a variety of parameterizations. For BEV, the electric machine power remains constant in the optimization procedure but the capacity and energy density of the battery are varying. To implement the RE machine and generator, it is necessary to simulate combustion engines and $E$ machines with corresponding dimensions. Thus, combustion engine and motor features have to be formulated in a variable way.

The size of the energy converter is controlled by nominal power and power density. Figure 7 visualizes an example of the electric machine scalings. It has to be kept in mind that the scaling is liable to certain limits: for instance, the efficiency of the electric machine reduces with decreasing nominal power.

The traction battery dimensioning is implemented by applying a Ragone diagram, showing power density and the energy density. The required nominal power of the electric machine is known from the required traction power. Hence, the battery power can be concluded. It permits to estimate the power-to-energy ratio which is needed to derive the battery capacity variation, the electric driving power variation, and consequently, 


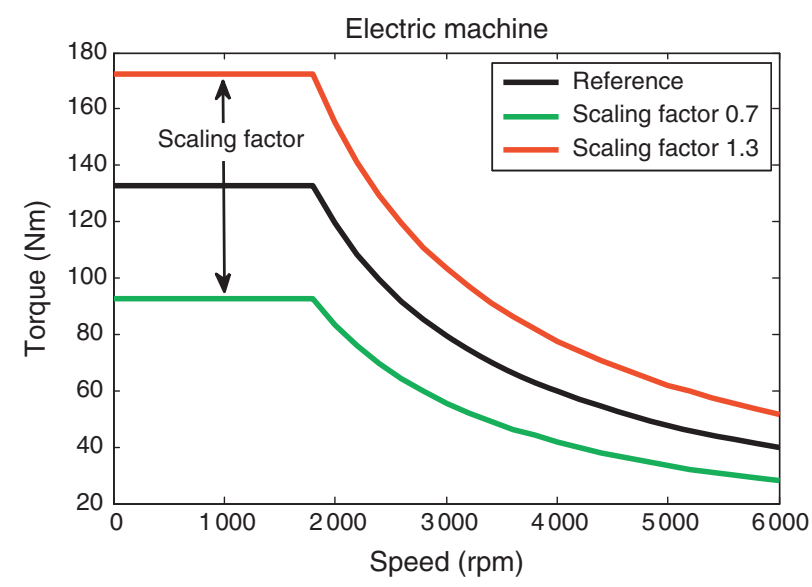

Figure 7

Scaling of electric machine and engine.

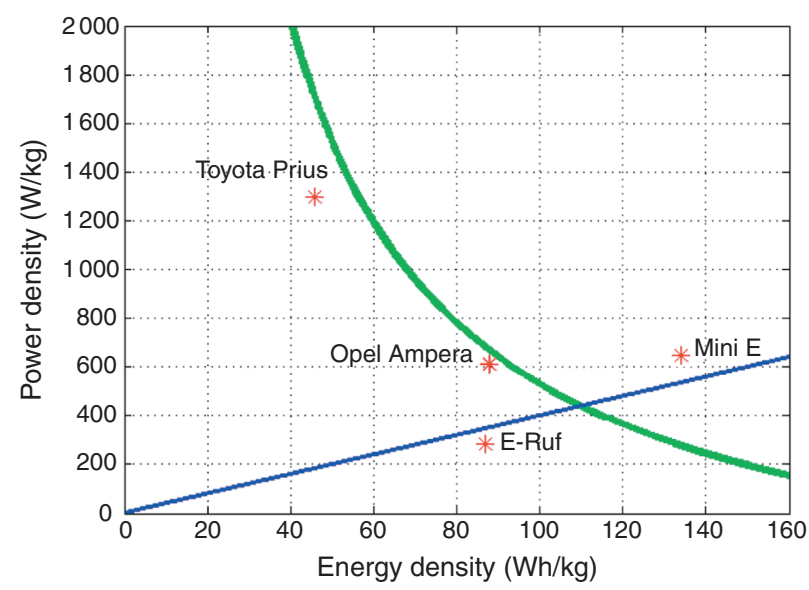

Figure 8

Power density versus energy density of lithium ion battery modules (green curve) and for an REEV50 (blue line). For comparison, characteristics of current $\mathrm{xEV}$ are included (red stars).

the battery weight. Figure 8 visualizes the power density to energy density ratio (green curve) of lithium ion battery modules (periphery included). The blue line refers to the power to energy ratio of an REEV50 battery. The intersection point leads to the requested specific power and specific energy, which can be used to derive the battery weight. The red stars flag current examples of $\mathrm{xEV}$ batteries, revealing a strong heterogeneity.

For each drive train configuration the vehicle mass has to be re-assessed. This procedure is realized via an automated iteration, executed in MATLAB ${ }^{\circledR}$. It should be noted, that the dimensioning of the energy storage system is the most important issue when analyzing $\mathrm{xEV}$, because their main advantages (lower operating costs and exhaust gas emissions) result from the usage of electric energy from the utility grid. The higher the all electric range of these $\mathrm{xEV}$, the higher is the potential to reduce operating costs and exhaust gas emissions. Therefore, BEV with batteries providing a high energy storage capability may seem to be best suited to meet the target. But high energy storage not only results in much higher battery costs but also yields a higher energy consumption due to the additional weight. For these reasons oversizing the battery needs to be avoided. On the other hand reducing the all electric range of $\mathrm{xEV}$ lowers the potential of fuel consumption reduction. Applying small batteries means to require high power cells which are more costly than high energy cells. The variables energy, power and usable SOC have to be considered, and this can only be done with respect to the user's driving patterns.

Hence, the total efficiency of REEV is controlled by the driving cycle and the $\mathrm{CSM} / \mathrm{CDM}$ ratio. This demands knowledge about the velocity-time-profile as well as charging times. This information can be retrieved from the TU-veLOG data. They allow for developing scenarios of recharging at the grid. According to [8] private users prefer nighttime charging. Consequently, the frequency distribution of diurnal driving distances has to be known for the optimization of PHEV and REEV electric ranges.

\section{APPLICATION}

To show the relevance and influence of the individual differences of vehicle usage on the efficiency, the above described optimization procedure is first applied to the group of private users and then to particular members of this group. Therefore, scalable simulation models of a compact class BEV and REEV are used. First, the user data and the individual driving cycles are evaluated to investigate the influences of the group's requirements on the drive train dimensioning of a BEV. Here, the above mentioned driving cycle was applied to dimension the battery. The presented battery costs base on 2015 estimations according to [9].

The analysis reveals that selecting a battery which allows to cover $95 \%$ (BEV 100) of all trips on pure electric driving compared to a smaller battery covering $91 \%$ for BEV 70 would excessively enhance the battery costs (Tab. 3). Moreover, the energy consumption would increase significantly due to the larger vehicle mass (and the higher portion of motorway driving at long trips). Nevertheless, the electrically driven distance would be only about $65 \%$ of the total driven kilometrage 
TABLE 3

Dimensioning of BEV-battery

\begin{tabular}{|c|c|c|c|c|c|}
\hline Range (km) & 50 & 70 & 100 & 150 & 350 \\
\hline Battery capacity (kWh) & 10.3 & 14.6 & 21.2 & 32.6 & 84.5 \\
\hline Battery weight $(\mathrm{kg})$ & 118.3 & 154.5 & 208.0 & 297.6 & 690.5 \\
\hline Battery costs (Euro) & 5103 & 6617 & 8949 & 12990 & 31365 \\
\hline Cons. $(\mathrm{kWh} / 100 \mathrm{~km})$ & 18.29 & 18.48 & 18.78 & 19.26 & 21.41 \\
\hline Days covered $(\%)$ & 86 & 91 & 95 & 96 & 99 \\
\hline Distance covered (\%) & 47 & 56 & 65 & 70 & 88 \\
\hline Amortisation time (a) & 6.9 & 8.6 & 11 & 14.7 & 28 \\
\hline
\end{tabular}

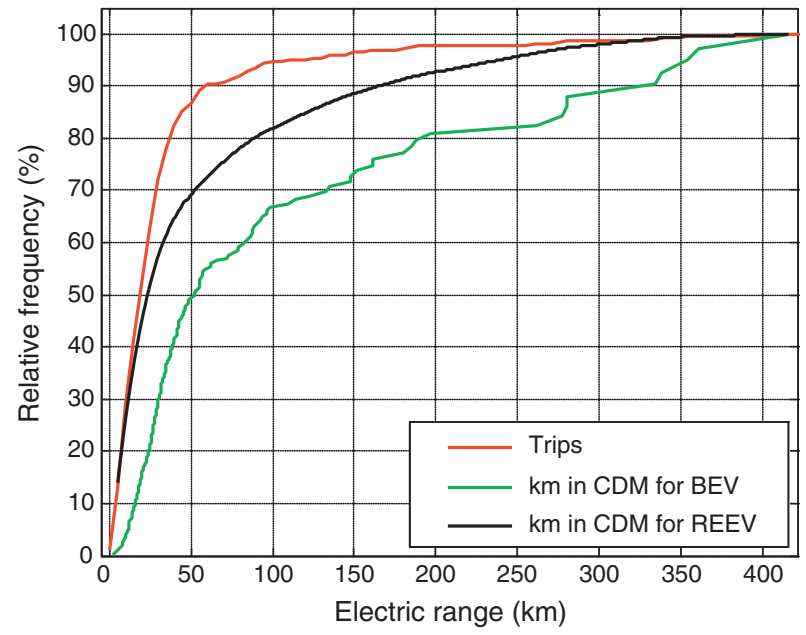

Figure 9

Ratio of distances and kilometers that can be driven in CDM for BEV (green) and REEV (black).

if it is assumed that in case of trips exceeding the BEV maximum range a substitute is used. A further increase in range would boost costs and consumption to an unreasonable level. Consequently, it could be more efficient to use a REEV with a small battery instead of a $\mathrm{BEV}$ to cover the given distances. This would provide another advantage compared to the BEV: the REEV is not constrained by a maximum range, thus it is no problem to cover distances that exceed the maximum electric range. A part of these trips is driven in CDM. Consequently, the electrically driven distances on REEV long trips significantly exceed these of a combination of BEV and substitute (Fig. 9).
Figure 9 can be interpreted as follows: as a conclusion from the analysis of parking positions and standing times (cf. Fig. 1 and [8]), nighttime charging was selected as the charging scenario for the considered user group. Hence, the BEV can only be used for day trips that do not exceed the maximum range. In case of all days, for which longer distances have to be covered, a substitute (e.g. second car) has to be used. In contrast, the REEV is able to cover all distances. If a long trip is scheduled, it can run a certain part of it on pure electric driving and the rest in CSM. For example, it can be learned from Figure 9 that at a given range of $50 \mathrm{~km}$ the BEV would cover $50 \%$ of the kilometers (correspondingly $90 \%$ of all daily distances). The REEV 50 is able to cover $100 \%$ of all daily distances and out of it $70 \%$ of the kilometers in CDM.

The drive train was dimensioned for a REEV, applying the battery cost efficiency as the target function. It can be determined for different ranges by incorporating the group's individual driving cycles, the frequency distribution of the distances and the cumulated distances. It has to be emphasized that the procedure does not comprise a Total Cost of Ownership (TCO) analysis but faces the purchase costs on the one hand and the operational costs due to consumption and energy prices on the other hand. The key point is to show the individual usage profile's impact on an efficiency balance. Thus, assumptions for discounting and declining balance have not been considered (yet).

Therefore, the curves shown in Figure 10 result from the following equation, where AC describes the cost of mobility after a certain driven distance $\mathrm{km}_{\text {driven }}$, Cost Bat $_{\text {Ba }}$ the battery purchase price, Cost $_{k m_{-} C D M}$ the energy cost per kilometer in CDM and $k m_{C D M}$ the percentage of kilometrage driven in CDM: 


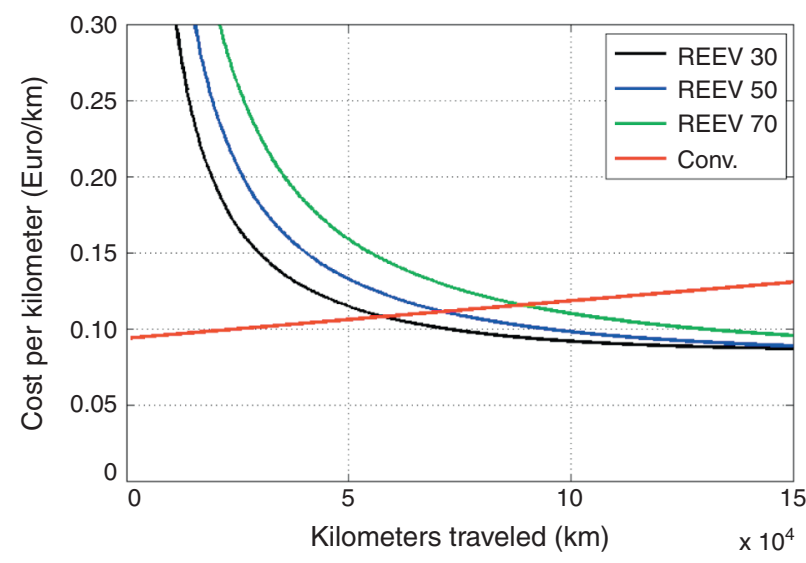

Figure 10

Operating costs of REEV and conventional vehicle.

$$
\begin{aligned}
A C= & \frac{\text { Cost }_{\text {Bat }}}{k m_{\text {driven }}}+\left(\text { Cost }_{k m_{2} \_C D M} \cdot k m_{C D M}\right) r \\
& +\left(\text { Cost }_{k m_{2} \_S M} \cdot k m_{C S M}\right)
\end{aligned}
$$

The curves for three REEV with different ranges, show costs per kilometer combined with the battery purchase price and the costs per kilometer curve for the reference conventional vehicle (red curve). For economical reasons no battery change is considered during the vehicle's life time.

The increase of costs per kilometer for the conventional vehicle and the amortization curve for the REEV (after reaching the minimum) is related to the future fuel/ electricity price development. According to the basic scenario in [4], a fuel cost increase from 1.42 Euro in 2010 up to 1.87 Euro in 2020 was assumed.

The intersection points of the red line and the decreasing curves in Figure 10 represent the time distances (translated to kilometers traveled) of amortization. Since no intersection points between the REEV curves can be found above the red line, it can be concluded that the REEV with the smallest battery will be amortized first compared to the conventional car. Considering the amortization times of different REEV reveals that such with larger batteries might be paid off earlier than the smallest REEV for a large amount of kilometers traveled, since they can cover more kilometers by electric ( = cost-efficient) driving. Here, limitation due to battery life time has not been taken into account. The battery costs of the different REEV concepts are addressed in Figure 11. They are based on assumptions for the year 2015 following [9] and estimated using the approach in [10] concerning the battery dimensioning. According to

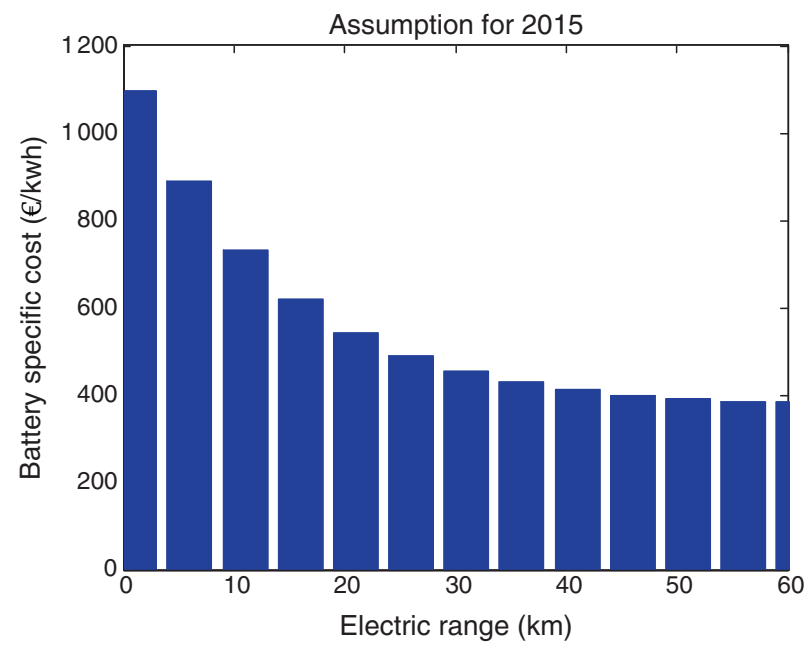

Figure 11

Specific battery cost for REEV.

[11] and [12], the initial costs of the other components of a compact class car differ marginally: considering car body, combustion engine and power train, tank, E machine and power electronics, respectively, costs for the conventional reference car will sum up to $16320.00 €$ while the BEV will cost $17203.50 €$ and the REEV will cost $17353.00 €$ (except battery).

The top panel of Figure 12 presents the battery amortization time versus the electric range for three fuel cost scenarios. The distribution results from the intersection of the REEV and the conventional vehicle in Figure 10. To transform the kilometrage into years, a yearly kilometrage of $10000 \mathrm{~km}$ is assumed, following [13]. The bottom panel of Figure 12 depicts the $\mathrm{CO}_{2}$ emission per $\mathrm{km}$, where the red line visualizes the $\mathrm{CO}_{2}$ emission of the conventional reference car. The emission optimum concerning $\mathrm{CO}_{2}$ occurs at an electric range of approximately $40 \mathrm{~km}$ (REEV) or $100 \mathrm{~km}$ (BEV), respectively, assuming that distances higher than the BEV range would be covered with a conventional car. It would be connected to a comparably high purchase price. Similarly, higher electric ranges would decrease the ecologic benefit, since the additional battery weight would increase the energy consumption and consequently, the $\mathrm{CO}_{2}$ emission. The emission calculation includes the emission of 563 grams of carbon dioxide per kilowatt hour electricity consumed for battery-charging. This implies that using REEV with an electric range less than $180 \mathrm{~km}$ instead of BEV + conventional cars would lead to less $\mathrm{CO}_{2}$ emission. 


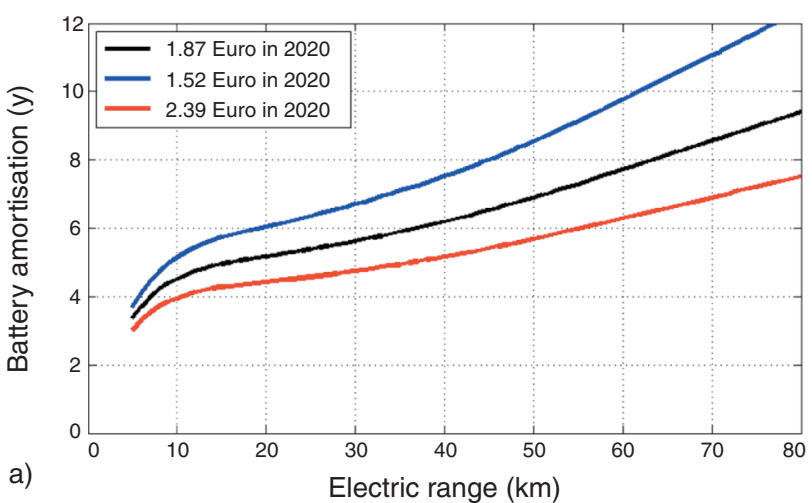

a)

Figure 12

a) Amortisation of battery cost and b) $\mathrm{CO}_{2}$ emissions for REEV.

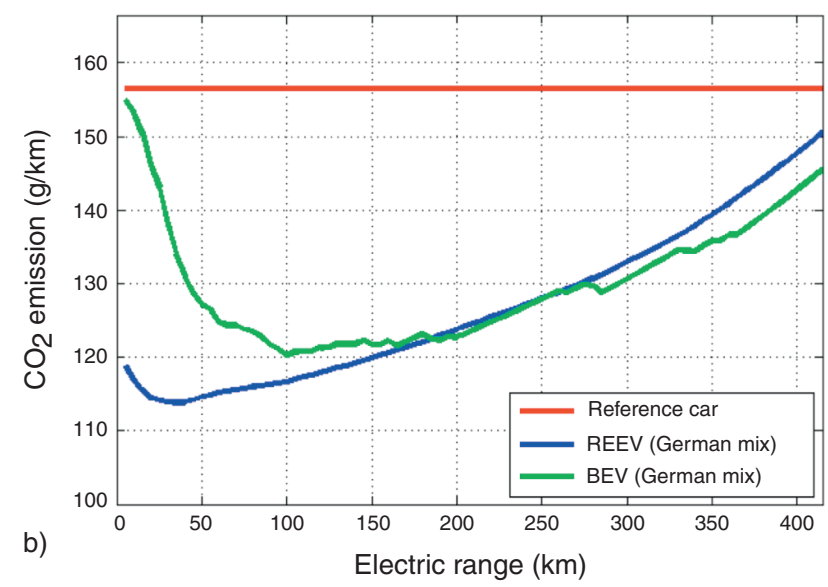

TABLE 4

Selected results for the whole group and two individuals from the same group

\begin{tabular}{l|c|c|c}
\hline & Group & Inter-urban driver & Urban driver \\
\hline Average speed $(\mathrm{km} / \mathrm{h})$ & 39.5 & 37.5 & 30.3 \\
\hline Cons. CDM REEV 50 $(\mathrm{kWh} / 100 \mathrm{~km})$ & 19.1 & 19.4 & 16.7 \\
\hline Cons. CSM REEV 50 $(\mathrm{L} / 100 \mathrm{~km})$ & 6.0 & 6.2 & 5.5 \\
\hline Cons. reference $(\mathrm{L} / 100 \mathrm{~km})$ & 6.59 & 6.94 & 5.66 \\
\hline Km in CDM for REEV 50 $(\%)$ & 47 & 64 & 83 \\
\hline Km in CSM for REEV 50 $(\%)$ & 3 & 36 & 17 \\
\hline Bat. capacity $(\mathrm{kWh})$ & 10.8 & 11 & 9.4 \\
\hline Amortisation time $(\mathrm{y})$ & 5.9 & 5.5 & 8 \\
\hline $\mathrm{CO}_{2}$ emission $(\mathrm{g} / \mathrm{km})$ & 114.5 & 122.2 & 100 \\
\hline
\end{tabular}

Subsequent to the battery dimensioning for the complete user group it should be investigated whether the results apply to all users of this group. Therefore, the data set of two particular users out of this group is analyzed. The driving profile of the urban driver is characterized by a large amount of intra-urban driving. The inter-urban driver also comprises motorway cycles. The results are gathered in Table 4 and Figure 13.

Table 4 reveals some, rather small differences in the consumptions, because the vehicles operate in the same metropolitan area. Nevertheless, there is a significant difference in the battery amortisation time between the urban driver and the inter-urban driver as well as between the urban driver and the whole group. Although the consumption in CDM leads to nearly the same battery sizes in the REEV 50 for the inter-urban driver and the urban driver, there is a divergency of 2.5 years in the amortisation curves (Fig. 13). The reason can be found in the portion of CDM and CSM for both drivers (Tab. 4). The urban driver travels $83 \%$ (compared to $64 \%$ for the interurban driver) in CDM and thus has lower operational costs. This result emphasises the importance of individual usage pattern when dealing with xEV.

Last but not least the battery ageing should be addressed in brief. It plays an important role in every efficiency balance, since it directly impacts the declining balance of a xEV. It has to be ensured that the battery lifetime does not undercut the vehicle lifetime significantly. The lithium ion battery ageing is very complex, 


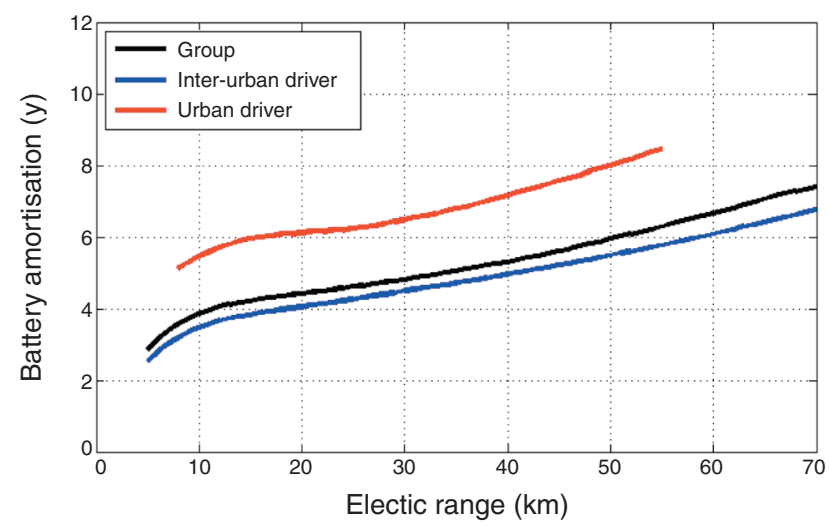

Figure 13

Amortisation of battery cost for the whole group and two individuals from the same group.

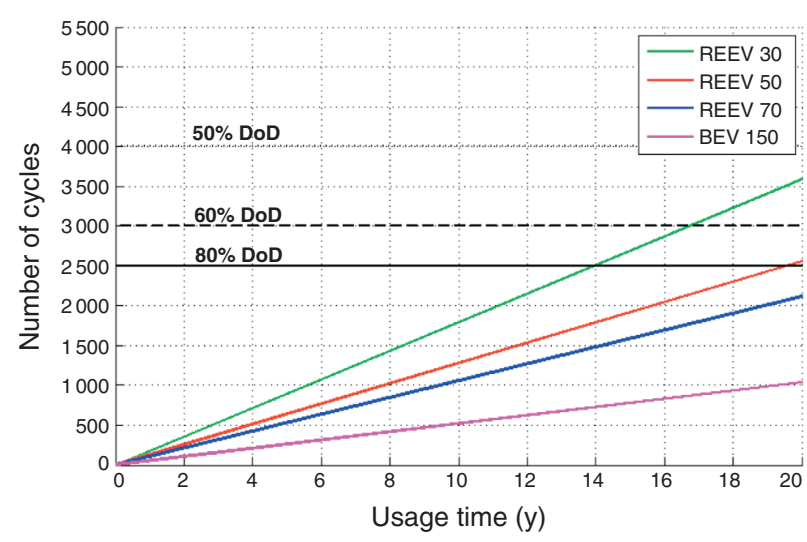

Figure 14

Number of deep discharge cycles derived from the group's distribution of daily driven distances. thus requiring complex ageing models. In this study, a very rough estimation of battery ageing is applied. The time dependent ageing is assumed to be constant, while the cycle ageing is determined by a full cycle probability curve gained of user data (frequency distribution of the trips and the electric range).

Figure 14 shows the number of deep discharge cycles derived from the group's usage pattern for REEV with different electric ranges. It is based on the mean value of daily driven distances of the group which was multiplied by 365 to obtain the yearly kilometrage roughly. REEV are then characterized by a yearly kilometrage of $12050 \mathrm{~km}$. BEV, only covering distances $<150 \mathrm{~km}$, attain a yearly kilometrage of $11028 \mathrm{~km}$. Since small batteries tend to experience more deep discharge cycles than bigger ones, they also reach their end of life much earlier, when the Depth of Discharge (DoD) is consistent across the battery sizes. In order to improve their cycle life, small batteries should feature lower depths of discharge. Nevertheless in this study, a DoD of $80 \%$ was chosen for all battery sizes. Figure 12 and 14 show, that the battery life time exceeds the battery amortization by far. Future work will incorporate a more precise ageing model.

\section{CONCLUSIONS AND DIRECTIONS FOR FUTURE RESEARCH}

This study shows that the user behaviour has direct and significant impact on the consumption efficiency of vehicles with electrified drive trains. For a detailed presentation of the consumption efficiency information about the user group-related individual driving cycles, driving characteristics (distribution of drivers) and charging behavior is required. It allows for estimating the user-specific optimal drive train configuration, thus providing the opportunity to reduce amortisation time and $\mathrm{CO}_{2}$ emission of grid-charged electric vehicles.

Further analysis is intended to investigate the significance of individual differences in the driving behaviour. OEM usually offers a variety of options for the drive train to chose among for a given vehicle. A 100\% individual configuration is not practised and hardly feasible in reality. Hence, it has to be examined, what kind of options in drive train configuration (e.g. battery dimension) would be suited to meet the needs of different user groups.

\section{ACKNOWLEDGMENTS}

We highly acknowledge C. Günther and A. Jossen from ZSW Ulm for providing battery information. The authors are supported by the BMWi via the project NET-ELAN.

\section{REFERENCES}

1 Hartmann B., Renner C. (2009) Conventional HEV, PlugIn or Range Extender? A Conceptual Comparison of Modern HEVs Based on Simulations, 18. Aachener Kolloquium Fahrzeug- und Motorentechnik, Aachen, Germany, 5-7 Oct.

2 Waldowski P., Schüppel F., Schindler V. (2010) Battery Optimisation in Electric Vehicles and Range Extended Electric Vehicles Based on Measured Individual Operational Profiles, VDE-Kongress, Leipzig, Germany, 8-9 Nov. 
3 Ernst C.-S., Lunz B., Hackbarth A., Madlener R., Sauer D.U., Eckstein L. (2010) Optimal Battery Size for Serial Plug-in Hybrid Vehicles: A Model-Based Economic Analysis for Germany, FCN Working Paper No. 14/2010.

4 Klötzke F. (2011) Fallstudie zur preislichen Wettbewerbsfähigkeit von Elektrofahrzeugen im gewerblichen Flottenmarkt bis 2020, Diploma Thesis, TU Berlin.

5 Schüppel F., Marker S., Waldowski P., Schindler V. (2010) TU veLOG: A Small Competitive Autarkic GPS Data Logging System, Advanced Microsystems for Automotive Application ( $A M A A)$, Berlin, Germany, 10-11 May.

6 Andre M. (2004) The ARTEMIS European driving cycles for measuring car pollutant emissions, Sci. Total Environ. 334-335.

7 Grüner J. (2010) Erstellung eines Modells zur automatischen Generierung eines individuellen Fahrzyklus mit Hilfe von Geschwindigkeitsprofilen aus Langzeitversuchen, Seminar Thesis, TU Berlin.

8 Hoberg P., Leimeister S., Jehle H., Krcmar H. (2010) Elektromobilität 2010 - Grundlagenstudie zu Voraussetzungen der Entwicklung von Elektromobilität in der Modellregion München, Baseline Survey, fortiss GmbH, TU München.

9 Bickert S., Günther C. (2011) Total Costs of Ownership von Elektrofahrzeugen unter besonderer Berücksichtigung von Batteriekosten, Wertverlust und Batteriealterung, HdTTagung ,Kraftwerk Batterie - Lösungen für Automobil und Energieversorgung“, Aachen, Germany, 1-2 March.

10 Delucchi M. (2000) Electric and Gasoline Vehicle Lifecycle Cost and Energy-Use Model, Final Report for the California
Air Resources Board, Institute of Transportation Studies, University of California, Davis.

11 Linßen J., Schulz A., Mischinger S., Maas H., Günther C., Weinmann O., Abbasi E., Bickert S., Danzer M., Hennings W., Lindwedel E., Marker S., Schindler V., Schmidt A., Schmitz P., Schott B., Strunz K., Waldowski P. (2012) Netzintegration von Fahrzeugen mit elektrifizierten Antriebssystemene in bestehende und zukünftige Energieversorgungsstrukturen, Advances in System Analyses 1, Energy Environ. 150, ISBN 978-3-89336-811-2.

12 Blesl M., Bruchhof D., Hartmann N., Özdemir E.D., Fahl U., Eltrop L., Voß A. (2009) Entwicklungsstand und Perspektiven der Elektromobilität, Stuttgart: Universität Stuttgart, Institut für Energiewirtschaft und Rationelle Energieanwendung, http://elib.uni-stuttgart.de/opus/ volltexte/2010/5218/.

13 Infas \& DLR (2010) Mobilität in Deutschland 2008, Final Report, Bonn, Berlin, infas Institut für angewandte Sozialwissenschaft $\mathrm{GmbH}$, Deutsches Zentrum für Luft- und Raumfahrt e.V. (DLR), Institut für Verkehrsforschung, http://www.mobilitaet-in-deutschland.de/pdf/MiD2008 Abschlussbericht_l.pdf and data base http://www.mobilitaet-in-deutschlañd.de/02_MiD2008/index.htm (16 April 2012).

Final manuscript received in December 2012 Published online in April 2013 